DOI: 10.12797/SI.13.2014.13.34

\author{
Bożenna Papis \\ Uniwersytet Warszawski \\ bpapis@uw.edu.pl
}

\title{
O tratamento das formas de tratamento nas aulas de português língua estrangeira
}

\section{Resumo:}

As formas de tratamento estão ligadas mais a uma determinada sociedade e sua cultura do que à própria língua à qual pertencem. Têm a ver com os comportamentos humanos e as relações interpessoais e assim como estes evoluem, aquelas atravessam constantes mudanças. Sendo o sistema das formas de tratamento do Português europeu muito rico, o seu ensino torna-se um verdadeiro desafio. E não se trata somente das formas lexicais, é todo um conjunto de fatores pragmáticos e socioculturais que, a elas unidos, favorece a criação e manutenção de um ambiente cooperativo que é o primeiro passo de uma comunicação bem-sucedida e essencial no uso da língua. Para assim ser, tanto as formas lexicais de tratamento, como os fatores pragmáticos e socioculturais, formam a matéria de ensino/aprendizagem única no seu tratamento nas aulas de Português língua estrangeira.

Palavras-chave: competência, interação, cortesia, formalidade, informalidade. 


\begin{abstract}
:
The treatment of the forms of treatment in the classes of Portuguese as a foreign language

The terms $\mathrm{T}$ and $\mathrm{V}$, based on the Latin pronouns $t u$ and vos, are more connected with a specified society and its culture than with the language they belong to. The terms concern human behaviours and interpersonal relations and they change constantly as the relations evolve. The system of T-V terms in European Portuguese is very rich, that is why its teaching is a true challenge. It is not really about the lexical terms, it is a combination of pragmatics and sociocultural factors, which, connected to them, promotes the creation and the maintenance of cooperative domain as the first step to a successful communication essential in the usage of the language. To be so, the lexical T-V terms, as well as the pragmatics and sociocultural factors, create the unique matter of teaching/learning at classes of Portuguese as a foreign language.
\end{abstract}

Keywords: competence, interaction, politeness, formality, informality.

\title{
Quando se trata das formas de tratamento, não podemos deixar de tratar das competências comunicativas numa língua
}

O Quadro Europeu Comum de Referência para as Línguas (QECRL) dá muita importância à aquisição de competências numa língua estrangeira, competências definidas como o conjunto dos conhecimentos, capacidades e caraterísticas que permitem a realização de ações. As pessoas, em sua função de interlocutores/participantes numa situação comunicativa, de um lado locutores / emissores de mensagens, do outro lado alocutários / recetores das ditas mensagens,

(...) utilizam as competências à sua disposição em vários contextos, em diferentes condições, sujeitas a diversas limitações, com o fim de realizarem actividades linguísticas que implicam processos linguísticos para produzirem e/ou receberem textos relacionados com temas pertencentes a domínios específicos. Para tal, ativam as estratégias que lhes parecem mais apropriadas para o desempenho das tarefas a realizar. O controlo 
destas ações pelos interlocutores conduz ao reforço ou à modificação das suas competências [Alves, 2001: 29].

As competências comunicativas em língua permitem a um indivíduo agir, utilizando especificamente meios linguísticos. O controlo dessa atuação tem a ver com as interações sociais dos indivíduos como participantes numa situação comunicativa. Erving Goffman, no artigo On Face-Works: An analysis of ritual elements in social interaction, apresentou as características das interações sociais dos indivíduos. $\mathrm{O}$ autor argumentou que as relações sociais que se estabelecem entre os indivíduos, tanto nos encontros imediatos como nas comunicações indiretas, devem ser analisadas rigorosamente. Para ele o desempenho dos papéis sociais tem a ver com o modo como cada indivíduo concebe a sua imagem e pretende mantê-la, introduzindo assim o conceito de footing, que é a forma de exprimir a relação entre a linguagem em uso (discurso) e a indexação, ou seja, o processo através do qual relacionamos os enunciados a momentos, lugares e agentes sociais. É a projeção do 'eu' de um locutor na sua relação com o outro, consigo próprio e com o discurso em construção, tentando produzir uma imagem positiva no seu alocutário, de modo a ser aceite por ele. Goffman refere que os membros de uma sociedade esperam dos outros a capacidade ou a competência linguística de trabalhar a face, a que habitualmente se chamava "tato", "saber fazer", "diplomacia" ou "aptidão social", e com isso antecipou a noção de cortesia, delicadeza ou polidez linguísticas.

A teoria de social face é continuada por Penelope Brown e Stephen C. Levinson. Para eles só existem atos de fala que prejudicam ou favorecem a imagem (face) dos alocutários. Por exemplo, os atos de fala diretivos serão sempre atos descorteses, ou como chamá-los, os atos ameaçadores da face. Nesta linha de análise a cortesia e as formas de tratamento como sua maior manifestação são vistas como um conjunto de estratégias que se propõe preservar a face, a tal social face, ou combater os atos ameaçadores dela. As estratégias da cortesia positiva são orientadas para darem uma imagem positiva de locutor, aliás as formas de tratamento têm essa finalidade. 


\section{Os locutores portugueses terão uma imagem positiva de acordo com a teoria de social face?}

Todo o sistema das formas de tratamento em Português europeu devido à sua variedade e riqueza é a prova de que a imagem dos portugueses é positiva de acordo com a teoria de social face. Aliás, além das formas de tratamento, há também as pré-sequências conversacionais, os sinais ou marcadores de alternância de vez, o uso dos eufemismos ou dos diminutivos e a utilização de certos verbos modais, bem como dos tempos mais utilizados na cortesia: o pretérito imperfeito e o condicional ou futuro do pretérito. Quanto à questão das formas de tratamento, que em Português europeu é bastante complexa, ela é um dos temas mais abordados, do ponto de vista morfossintático, semântico-pragmático ou sociolinguístico, por estudiosos portugueses e estrangeiros.

O locutor, quando se dirige ao alocutário, tem de ter em conta o conjunto dos papéis sociocomunicativos, como as diferenças sociais, de idade, a proximidade ou a distância da relação, a formalidade ou informalidade da situação discursiva. Através das formas de tratamento, valoriza-se positiva ou negativamente o alocutário, sendo que elas regulam as relações intersubjetivas e permitem perceber a subjetividade enunciativa.

O princípio da cortesia, analisado por Geoffrey Leech entre os vários princípios conversacionais, é referido pelo autor, aliás de acordo com Goffman, da seguinte forma:

(...) politeness is manifested not only in the content of conversation, but also in the way conversation is managed and structured by its participants. For example, conversational behaviour such as speaking at the wrong time (interrupting) or being silent at the wrong time has impolite implications. Consequently we sometimes find it necessary to refer to the speech acts in which we or our interlocutors are engaged, in order to request a reply, to seek permission for speaking, to apologize for speaking, etc. [Leech, 1983: 139]. 
No Português europeu existem muitas construções linguísticas motivadas pela cortesia linguística. A cortesia pode estar em todos os usos linguísticos e em todos os atos comunicativos interpessoais (mesmo nos atos diretivos). Ela depende do contexto em que ocorrem, mas também é estabelecida pelas intenções comunicativas e estratégicas do locutor e pela relação social entre os interlocutores.

As expressões de cumprimento ou de pré-sequências conversacionais são muito recorrentes no Português europeu. Acontecem quando o locutor tenta evitar a divergência do alocutário, uma atitude discordante à sua pessoa ou mesmo a sua antipatia. Como a cortesia funciona primeiramente no discurso conversacional oral espontâneo, todas as estratégias de alternância de vez devem ser tidas em conta e com ela as formas de tratamento.

\section{Ensinar a falar é também ensinar a empregar as formas de tratamento}

Segundo Maria Ricardo Marques a língua portuguesa continua "a ter dois pólos orientadores das escolhas designativas de o outro: por um lado é poder/status, por outro é solidariedade" [Marques, 1988: 44]. A autora considera os fatores sociais, como a idade, o estatuto social ou o nível profissional como essenciais no tratamento de pessoas adultas marcado pela deferência e hierarquia.

Nos atos de fala as formas de tratamento desempenham um papel importante, já que no seu uso entram também fatores sociais e culturais. Por isso mesmo, ao ensinar aos estudantes estrangeiros a língua portuguesa, elas se tornam um tema didático muito complexo, merecendo particular atenção. Isabel Margarida Duarte sublinha que: "As formas de tratamento são, em português, um item de reconhecida dificuldade, não só no que concerne à sua tradução para outras línguas, mas também no que diz respeito ao ensino da língua, quer enquanto língua estrangeira quer enquanto língua materna" [Duarte, 2010: 133]. 
As dificuldades estão não somente no emprego das formas de tratamento, mas também na manutenção da uniformidade de tratamento, devido à sua extensa variedade. A maior parte dos problemas para os alunos de PLE é de tipo pragmático e decorre do facto de não saberem adequar a forma própria ao destinatário relacionado social e linguisticamente com o emissor. Mas, para que o locutor saiba empregar a forma adequada por meio da qual se deve dirigir ao alocutário, tem de possuir, no seu acervo lexical, um conjunto rico e variado de alternativas pelas quais possa optar, depois de avaliar devidamente a situação enunciativa, o estatuto e a relação entre os interlocutores entre os quais decorre a troca comunicativa. Esse acervo lexical é dado nas aulas, sempre com o devido esclarecimento acerca dos fatores culturais que não podem ser omitidos.

No decurso das minhas pesquisas, dirigidas aos alunos de nível inicial, foram propostas atividades de produção textual em que estaria presente o emprego das formas de tratamento. Ao desenvolvermos tais atividades nas aulas, foi analisado o material produzido pelos alunos para verificar as opções realizadas ao empregarem os pronomes de tratamento nos textos produzidos, observando assim como se apresenta a questão da uniformidade de tratamento: se esta é mantida e quais as dificuldades relacionadas ao processo de escolha por uma 'variedade' de tratamento em língua portuguesa. Também foram pedidas algumas produções de diálogos que envolviam apresentações, saudações e despedidas, opiniões acerca de gostos, tendo sempre em conta o nível iniciante dos alunos. Foi trabalhado, além do conteúdo vocabular, o conteúdo gramatical sobre os pronomes de tratamento em língua portuguesa. Primeiro explicou-se quais os pronomes pessoais do idioma, para em seguida ser explicado um ponto da variedade linguística que influencia o uso de tais pronomes em diferentes contextos, invocando igualmente a questão da formalidade e informalidade que tinha a ver com o distanciamento e proximidade entre os participantes da ação linguística.

Como se tratava de alunos do nível básico optou-se por diferenciar apenas as diferentes formas de tratamento entre falantes portugueses e brasileiros de forma generalizada, mas que já pudessem apontar e considerar as diferenças relevantes. 
Após a primeira fase de explicações e esclarecimentos, foram desenvolvidas as atividades práticas. Para este trabalho, partiu-se do pressuposto de que seria natural observar nos primeiros diálogos realizados uma certa dificuldade em manter uniformidade de tratamento, considerando o fator formal-informal, sendo que os alunos trocavam as formas da segunda e terceira pessoas. Depois, no Polaco a forma de tratamento na terceira pessoa é uniformizada, o que provoca maior confusão no emprego em Português, já que é preciso escolher entre você e o senhor/a senhora. Comprovou-se essa ocorrência na maioria das atividades produzidas. Através de outras produções textuais que se seguiram a esta atividade proposta, foi possível notar que aos poucos os alunos adquiriam mais cuidado ao produzirem os seus textos, utilizando as formas de tratamento mais adequadas a cada contexto e procurando manter uniformidade de tratamento. Sobre as atividades propostas acerca deste tema em alguns materiais didáticos observados, notava-se dificuldade em encontrar sugestões de produção textual que trabalhassem a questão das formas de tratamento. Talvez o motivo para isso seja a complexidade do assunto.

\section{Temas abordados}

A temática do Natal traz as formas de tratamento mais frequentes; são as saudações, expressões usadas em cartas formais e informais, trabalhadas através de categorização (pronominal, nominal e verbal), reflexão sobre o uso de $t u$ e você, produção de diálogos formais e informais, uso de fórmulas de saudação e de despedida, como também de algumas expressões de delicadeza em cartas formais e informais.

A temática das viagens dá multiplicidade de contactos formais e informais, sistematizando os usos de formas de tratamentos que neles ocorrem e os seus efeitos comunicativos ou utilizando-as em situações contextualizadas, sempre com o devido reconhecimento das formas corretas e o trabalho de correção das formas indevidas. 
A temática dos programas televisivos na oralidade e na escrita desenvolve o tratamento de você e o reconhecimento de múltiplas formas de cortesia nos contactos interativos devido à diversidade de situações e contextos dados; os alunos reproduzem esses contextos ou a partir deles criam novos, chegando assim a uma autonomia linguística de escolha das formas corretas.

A temática do emprego envolve variadíssimas formas de tratamento, já que aqui entram fatores sociais e profissionais mais marcantes. Nos diálogos propostos aos alunos são evidentes as diferenças no tratamento das pessoas conforme os cargos profissionais e hierárquicos que ocupam. O professor deve sensibilizar os alunos para verem nessas diferenças a realidade social e cultural que é preciso conhecer para respeitar.

\section{À laia de conclusão}

O papel do professor é sempre relevante na fase inicial do ensino de uma língua estrangeira, tanto mais quando se trata de um tema tão complexo como as formas de tratamento no Português europeu devido à sua diversidade. Os temas e textos propostos hão de dar conta dessa diversidade, constituíndo ao mesmo tempo uma amostra bem equilibrada da realidade linguística. A grande variedade das formas de tratamento existente na língua portuguesa faz com que a sua apresentação se torne um verdadeiro desafio para o professor, tanto mais que é um tópico dado aos alunos iniciantes. Acreditamos que é possível trabalhar e refletir sobre as suas adequações e uniformidades no uso efetivo da língua, possibilitando assim o sucesso didático ao falante de português língua estrangeira. 


\section{Referências bibliográficas}

ALVES, J. M. (ed.) (2001), Quadro Europeu Comum de Referência para as Línguas. Aprendizagem, ensino, avaliação, Edições Asa, Lisboa.

BROWN, P., LEVINSON, S. C. (1987), Politeness: Some universals in language usage, Cambridge University Press, Cambridge.

DUARTE, I. M. (2010), "Formas de tratamento: item gramatical no ensino do Português Língua Materna", em: Brito, A.M. (org.), Gramática: história, teorias, aplicações, Universidade do Porto, Faculdade de Letras, Porto, pp. 133-146.

GOFFMAN, E. (1955), "On Face-work: An Analysis of Ritual Elements of Social Interaction”, Psychiatry: Journal for the Study of Interpersonal Processes, 18, 3, Nova Iorque, pp. 213-231.

LEECH, G. N. (1983), Principles of Pragmatics, Longman, London-New York.

MARQUES, M. E. R. (1988), Complementação verbal. Estudo sociolinguístico (Tese de doutoramento), Faculdade de Ciências Sociais e Humanas da Universidade Nova de Lisboa, Lisboa.

MARQUES, M. E. R. (1995), Sociolinguística, Universidade Aberta, Lisboa. 